\title{
Pharmacy beyond the dispensary: general practitioners' views
}

\author{
John A Spencer, Clive Edwards
}

\begin{abstract}
Objectives-To ascertain general practitioners' attitudes to an extended role for community pharmacists.

Design-Postal questionnaire to a 1 in 6 sample of general practitioners in the Northern, West Midlands, and Oxford regions (total sample size 1087).

Main outcome measures-Attitudes towards specific extended roles, pharmacist prescribing of particular drugs, the role of the pharmacist, and the relationship between the professions.

Results -744 questionnaires were returned in a usable form, an overall response rate of $68.4 \%$. Attitudes varied, from a majority in favour of pharmacists reporting adverse drug reactions to a majority against their supervising repeat prescriptions ( $81 \%$ and $36 \%$ in agreement respectively). A similar range of attitudes was shown to pharmacist prescribing, from $84 \%$ in agreement with their prescribing nicotine chewing gum (deregulated since the survey) to $11 \%$ agreeing to their prescribing cimetidine. About half the respondents thought general practitioners should be allowed to dispense and a third that pharmacists "should stick to dispensing." $27 \%$ agreed that pharmacists were too influenced by commercial pressures to give unbiased advice.
\end{abstract}

Conclusions-Most doctors would favour an extension of the activities of community pharmacists but worry about their role in screening and counselling patients and in prescribing. Despite relationships being generally felt to be good, there may be a need for better communication and cooperation locally and for proper evaluation of initiatives to extend the role of the pharmacist.

\section{Introduction}

Every day roughly half a million people in the United Kingdom receive a prescription from their general practitioner before going to a pharmacy to have it dispensed. Despite this apparently close association of function, doctors and pharmacists are not perceived as working together, ${ }^{1}$ and many general practitioners do not regard the pharmacist as a potential member of the primary health care team. ${ }^{2}$ As well as patients with prescriptions, pharmacies are visited daily by over six million other people, ${ }^{\prime}$ offering numerous opportunities for health education and advice in an informal environment.

The Nuffield Committee of Inquiry into Pharmacy in $1986^{3}$ and the government's white paper on primary health care in $1987^{+}$both proposed extending the role of the community pharmacist into activities such as health education and screening, increasing their traditional role in advising about minor illness, supervising medication in nursing homes for the elderly, and advising general practitioners about cost effective prescribing. In addition pharmacists have long wanted the reclassification of an increasing number of "prescription only" drugs to allow them to prescribe for specific conditions from a limited formulary. ${ }^{5}$ The idea of an extended role for pharmacists was endorsed by the government in the NHS review ${ }^{6}$ and a joint working party of the Department of Health and the Royal Pharmaceutical Society, established in 1990 to explore the future of community pharmaceutical services, has recently issued a report covering many of these subjects. ${ }^{7}$ Such proposals have, however, received a variable response from the medical profession and continue to provoke debate. ${ }^{8}$

This paper presents the results of a survey of the attitudes of general practitioners to these extended roles carried out before the working party published its report.

\section{Methods}

In the autumn of 1990 after local piloting we sent a questionnaire to a one in six random sample of general practitioner principals in the Northern, Oxford, and West Midlands regions. General practitioners' names were obtained from family health services authority lists and selected using random numbers tables.

Attitudes were elicited to the following subjects: specific extended roles for pharmacists (10 questions); the supply of particular drugs by pharmacists in certain clinical situations without a prescription from the patient's doctor ( 14 clinical scenarios); the role of the pharmacist and the relationship between general practitioners and pharmacists (five statements). Respondents were asked to rate their attitudes on a five point Likert scale" ranging from "strongly agree" to "strongly disagree." The responses for the two agreement and disagreement categories were each combined into one category, giving three responses: agree, uncertain, and disagree. The data were analysed with the SPSS-X package using $\chi^{2}$ tests.

\section{Results}

A total of 1087 questionnaires were sent (Northern 291, Oxford 308, and West Midlands 488), of which 744 were returned in a usable form, an overall response rate of $68.4 \%$. (Oxford $75 \cdot 6 \%$, Northern $70 \cdot 4 \%$, and West Midlands $62 \cdot 7 \%$ ). Respondents were similar in years since qualification and size of practice as for the United Kingdom as a whole. In all regions, however, there was a slightly higher proportion of dispensing doctors among the respondents than in the total sample but this was significant only for West Midlands (table I). There were no significant differences in response by region to any of the questions, and the data were therefore aggregated.

The responses to the 10 questions about specific extended roles (table II) showed a range from very favourable attitudes towards pharmacists reporting adverse drug reactions, increasing their role in managing minor illness, and advising general prac-
Correspondence to:

Dr Spencer.

BMF 1992;304:1670-2 
titioners about cost effective prescribing to generally unfavourable reactions to pharmacists screening for raised blood pressure, hyperlipidaemia, and height and weight of preschool children. Opinion was more equally divided about pharmacists monitoring medicines in nursing homes for the elderly, screening for glycosuria, supervising repeat prescribing, and counselling patients taking long term benzodiazepines.

Responses to the questions about pharmacists prescribing certain drugs for specific conditions showed a similar range (table III). Most respondents agreed with pharmacists issuing nicotine chewing gum, codydramol (10 tablets for toothache), and oral nystatin (for oral candidosis in a baby). But few favoured the other suggestions - notably, their issuing propranolol for anxiety, cimetidine for dyspepsia not responsive to antacids, and antibiotics for sore throat and productive cough.

There was a high level of agreement that communication between pharmacists and general practitioners was good and that pharmacists were ideally placed to provide health education. Nevertheless, about half the respondents thought general practitioners should be allowed to dispense and a third that pharmacists "should stick to dispensing." Finally, there was a mixed response to the statement about pharmacists being biased by commerical pressures, with nearly a third in agreement (table IV).

TABLE I-General practitioners' responses to questionnaire. Values are numbers (percentages)

\begin{tabular}{|c|c|c|c|c|c|}
\hline \multirow[b]{2}{*}{ Region } & \multicolumn{2}{|c|}{ Questionnaires } & \multicolumn{2}{|c|}{ Dispensing doctors } & \multirow{2}{*}{$\begin{array}{l}\text { Odds ratio of likelihood } \\
\text { of dispensing doctors } \\
\text { responding to the } \\
\text { questionnaire }\end{array}$} \\
\hline & No sent & No usable & $\begin{array}{l}\text { No in total } \\
\text { sample }\end{array}$ & $\begin{array}{l}\text { No in } \\
\text { responders }\end{array}$ & \\
\hline Northern & 291 & $205(70 \cdot 4)$ & $58(19 \cdot 9)$ & $49(23.9)$ & $1 \cdot 26$ \\
\hline Oxford & 308 & $233(75 \cdot 6)$ & $62(20 \cdot 1)$ & $51(21.9)$ & $1 \cdot 11$ \\
\hline West Midlands & 488 & $306(62 \cdot 7)$ & $76(15 \cdot 6)$ & $67(21 \cdot 9)$ & $1 \cdot 52^{\star}$ \\
\hline
\end{tabular}

Total $1087 \quad 744(68.4)$

${ }^{\star} \chi^{2}=5 \cdot 3 ; \mathrm{df}=1 ; \mathrm{p}=<0 \cdot 025$

TABLE II-General practitioners' responses to suggestions about extended roles for community pharmacists. Values are percentages of respondents

\begin{tabular}{lcc}
\hline Extended role & Agree & Disagree \\
\hline $\begin{array}{l}\text { Reporting adverse drug reactions } \\
\text { Increased role in managing minor illness }\end{array}$ & 81 & 10 \\
$\begin{array}{l}\text { Advising general practitioners about cost } \\
\quad \text { effective prescribing }\end{array}$ & 66 & 18 \\
$\begin{array}{l}\text { Monitoring prescribing in nursing homes for } \\
\quad \text { the elderly }\end{array}$ & 61 & 28 \\
$\begin{array}{l}\text { Counselling patients taking long term } \\
\quad \text { benzodiazepines }\end{array}$ & 46 & 37 \\
$\begin{array}{l}\text { Screening for glycosuria } \\
\text { Supervising repeat prescriptions }\end{array}$ & 44 & 41 \\
Screening for raised blood pressure & 36 & 42 \\
Screening for raised blood lipid & 24 & 43 \\
$\quad$ concentrations & 18 & 65 \\
Screening preschool children for height and & 13 & 74 \\
$\quad$ weight & &
\end{tabular}

TABLE III-General practitioners' responses to prescribing by community pharmacists. Values are percentages of respondents

\begin{tabular}{|c|c|c|c|}
\hline Drug & Indication & Agree & Disagree \\
\hline Co-dydramol (10 tablets) & Severe toothache & 87 & 9 \\
\hline Nicotine chewing gum & Smoker wishing to stop & 84 & 9 \\
\hline Oral nystatin suspension & Oral "thrush" in baby & 63 & 28 \\
\hline Antifungal vaginal pessaries & Vaginal "thrush" in adult woman & 53 & 38 \\
\hline Chloramphenicol drops or ointment & Sticky red eye in infant $>2$ months & 52 & 39 \\
\hline Beclomethasone nasal spray & $\begin{array}{l}\text { Allergic rhinitis not responsive to } \\
\text { antihistamines }\end{array}$ & 46 & 41 \\
\hline Rectal suppositories containing steroids & Haemorrhoids & 43 & 42 \\
\hline Three day course of trimethoprim & Frequency and dysuria in adult woman & 35 & 54 \\
\hline Topical antibiotic & Weeping skin infection & 30 & 59 \\
\hline "Morning after pill" & $\begin{array}{l}\text { Unprotected intercourse within } 72 \\
\text { hours }\end{array}$ & 27 & 64 \\
\hline Five day course penicillin & Sore red throat in adult & 17 & 76 \\
\hline $\begin{array}{l}\text { Five day course broad spectrum } \\
\text { antibiotic }\end{array}$ & $\begin{array}{l}\text { Productive cough in otherwise healthy } \\
\text { young adult }\end{array}$ & 15 & 78 \\
\hline Cimetidine & $\begin{array}{l}\text { Dyspepsia in adult under } 45 \text { years not } \\
\text { responsive to antacids }\end{array}$ & 11 & 82 \\
\hline Propranolol $(10 \times 10 \mathrm{mg}$ tablets $)$ & Anxiety state in adult & 11 & 81 \\
\hline
\end{tabular}

TABLE IV-General practitioners' attitudes to community pharmacists. Values are percentages of respondents

\begin{tabular}{lcc}
\hline Statement & Agree & Disagree \\
\hline $\begin{array}{l}\text { Pharmacists are too influenced by commercial } \\
\text { pressures to give unbiased advice }\end{array}$ & 27 & 43 \\
$\begin{array}{c}\text { Pharmacists, as first point of contact for many } \\
\text { people, are ideally placed to provide health } \\
\text { education }\end{array}$ & 68 & 18 \\
$\begin{array}{c}\text { Communication between general practitioners } \\
\text { and pharmacists is generally very good }\end{array}$ & 73 & 13 \\
$\begin{array}{c}\text { Pharmacists should stick to dispensing and not } \\
\text { venture into other areas of medicine }\end{array}$ & 34 & 45 \\
$\begin{array}{c}\text { All general practitioners should be allowed to } \\
\text { dispense }\end{array}$ & 50 & 27 \\
\hline
\end{tabular}

\section{Discussion}

Although this survey was carried out before the joint working party produced its report, ${ }^{7}$ our results suggest that there will be a mixed response from the medical profession to its 30 recommendations. For instance, general practitioners reacted unfavourably to the idea of pharmacists carrying out screening procedures, whereas the working party, which encourages such developments, recommends that pharmacists should be paid for providing some screening services. Similarly, an extension of the pharmacist's supervisory role into areas such as repeat prescribing, a key recommendation of the report, was not favoured by general practitioners. There was, however, support for an increased role for pharmacists in three particular activities: managing minor illness, advising general practitioners, and reporting adverse drug reactions.

Firstly, managing minor illness is a traditional role in which pharmacists fulfil an important gatekeeper function. ${ }^{10}$ The public sees them as a valuable part of the network of lay health resources. ${ }^{11}$ Nevertheless, concern has been expressed not only about possible commercial influences, as in our study, but also about the quality of the advice given by some pharmacists for even simple conditions. ${ }^{1213}$ One way of helping to resolve these problems would be greater cooperation between doctors and pharmacists at local level-for instance, in drawing up protocols for responding to symptoms and, as advocated in the working party report, in the use of "pharmacy referral forms," the utility of which has already been shown. ${ }^{14}{ }^{15}$ Secondly, pharmacists already provide advice and support to practitioners about prescribing,${ }^{16}$ and this practice may increase as the drug information needs of general practitioners increase. ${ }^{17}$ The working party recommendation that all family health services authorities should appoint a pharmaceutical adviser is welcome but should not deter local initiatives. Thirdly, pharmacists are in an ideal position to report adverse drug reactions, ${ }^{15}$ and an extension of the formal reporting system to include them is long overdue.

We asked for opinions about pharmacists providing particular medicines without a prescription from a doctor. This would necessitate reclassifying these drugs from "prescription only" to "pharmacy" medicines, and such an arrangement offers several advantages. The patient benefits through easier access to professional help; general practitioners might spend less time dealing with minor complaints; and the NHS drug bill could be reduced.$^{18}$ Nicotine chewing gum, one of the medicines felt by our respondents to be suitable for such a change, was reclassified in 1991 after the survey was completed. Otherwise, apart from the provision of strong analgesics and oral nystatin, there was a mixed or negative response to the other suggestions.

Concern about declassifying drugs and pharmacist prescribing is not new and has its roots partly in the historical antipathy between the medical and pharmacy 
professions. ${ }^{19}$ Nevertheless, in some countries with a prescribing culture similar to that of the United Kingdom - for example, Denmark - a wider range of medicines (including several of those proposed in our survey) is available through pharmacies, to the apparent benefit of the public.?

Antagonism between the professions is perhaps best symbolised by the long standing conflict between dispensing doctors and pharmacists, who are potentially in competition for business; and representatives of dispensing doctors have been prominent in the debate about the future role of pharmacists. ${ }^{8}$ In our survey almost half the respondents thought that all general practitioners should be allowed to dispense. In fact a proposed amendment to the NHS bill that would have allowed this received a hostile reception from pharmacists ${ }^{20}$ and in the end was not passed, although the issue remains topical.

\section{CONCLUSION}

This survey suggests that general practitioners would support an extension of the role of the community pharmacist into a limited number of activities. At local level relationships between the professions are generally felt to be good, but closer cooperation and better communication might help improve the quality of the advice given to patients. Schemes to extend the role of the pharmacist are being introduced, such as the project to screen for diabetes using spot blood tests, ${ }^{21}$ but little research has been carried out into the efficacy, cost effectiveness, or acceptability of these schemes. ${ }^{2}$ Although developments are inevitable, thorough evaluation of new initiatives is also necessary. If evaluation took place alongside the changes in education and training that have been recommended, ${ }^{7}$ general practitioners would be reassured that any extension of the role of the pharmacist would benefit patient care and the public health.

We thank Dr Helen Wilson for her help and Mr Tim Butler, Dr David Parkin, Professor Michael Rawlins, and Dr
Gail Young for their advice. The study was funded by the scientific foundation board of the Royal College of General Practitioners.

1 Drury M. Doctors and pharmacists-working together. $\mathrm{Br}$ I Gen Pract 1991;41:91.

2 Morley A, Jepson MH, Edwards C, Stillman P. What do doctors think of pharmacists treating minor ailments? Pharm f 1983;231:387-8.

3 Nuffield Foundation Committee of Inquiry. Pharmacy: the report of a committe of inquiry appointed by the Nuffield Foundation. London: Nuffield Foundation, 198

4 Secretaries of State for Health, Wales, Scotland and Northern Ireland. Promoting better health. HMSO: London, 1987.

5 Pharmaceutical Services Negotiating Committee. The pharmacist's charter extending the role of the pharmacist in the provision of health care to the community. Aylesbury: Pharmaceutical Services Negotiating Services Committee, 1987

6 Secretaries of State for Health, Wales, Scotland and Northern Ireland. Working for patients. HMSO: London, 1989.

7 Joint Working Party on the future role of the community pharmaceutical services. Pharmaceutical care: the future for community pharmacy. London, 1992.

8 Roberts D. Dispensing by the community pharmacist: an unstoppable decline? $7 R$ Coll Gen Pract 1988:38:563-44.

9 Likert R. A technique for the measurement of attitudes. Psychology 1932: No 140 .

10 Elliott-Binns $C P$. An analysis of lay medicine: fifteen years later $f R$ Coll Gen Pract 1986;36:542-4

11 Cunningham-Burley S, Maclean U. Pharmacists and primary care: some research findings and recommendations. Fam Pract 1988;5:122-5.

12 Goodburn E, Mattosinho S, Mongi P, Waterston T. Management of childhood diarrhoea by pharmacists: is Britain lagging behind the Thir World? BMf 1991;302:440-3.

13 Consumers' Association. Pharmacists. How reliable are they? Which? way to health. 1991;Dec: 191-4.

14 Blenkinsopp A, Jepson M, Drury M. Using a notification card to improve communication between community pharmacists and general practitioners. Br f Gen Pract 1991;41:116-8.

15 Shulman JI, Shulman S, Haines AP. The prevention of adverse drug reactions - a potential role for pharmacists in the primary care team? $\mathcal{F} R$ Coll Gen Pract 1981:31:429-34.

16 Needham A, Brown M, Freeborn S. Introduction and audit of a general practice antibiotic formulary. $\mathcal{I} R$ Coll Gen Pract 1988:38:166-7.

17 Bradley CP. Doctors and pharmacists-working together. $\mathrm{Br} f \mathrm{Gen}$ Pract 1991;41:436

18 Ryan $M$, Yule B. Switching drugs from prescription-only to over-the-counter availability: economic benefits in the United Kingdom. Health Policy 1990;16:233-9.

19 Smith MC. The relationship between pharmacy and medicine. In: Mapes $\mathbf{R}$ ed. Prescribing practice and drug usage. London: Croom Helm, 1980

20 Tory MP wants all doctors to dispense under NHS. Pharm f 1990;244:255.

21 PSNC to run diabetes screening pilot study. Pharm f 1991;246:414

22 Edwards C. Blood pressure measurement by pharmacists. $\mathcal{F}$ R Coll Gen Pract $1981 ; 31: 674-6$

23 Rawlins M. Extending the role of the community pharmacist. BMf 1991;302 $427-8$.

(Accepted 15 May 1992)

\section{Managing Change in Primary Care}

\section{Practice managers and practice management}

\section{Lin Macmillan, Mike Pringle}

This is the sixth in a series of articles looking at how to manage change in general practice

\section{Newark NG24 1QD \\ Lin Macmillan, practice manager}

\section{Department of General Practice, Nottingham NG7 2UH}

Mike Pringle, senior lecturer

Series editor: Dr Mike Pringle.

BMf 1992;304:1672-4
Practice managers are something of a new breed. They are evolving into serious professionals at breakneck speed with, in many cases, considerable autonomy in running practices-practices which have turnovers similar to small or medium sized businesses.

Knowledge of the NHS and medical work is an advantage, but not essential. Training and experience in management skills is more useful, as these can be adapted to different environments without difficulty if the manager is flexible and willing to learn. One prime skill is that of reacting to, influencing, and modifying change within and outside the practice. In this article we look at the general role of the new practice managers and especially at those skills required in the management of change.

\section{Personal and personnel skills}

A successful practice manager will utilise all the wiles of a good general manager of any efficient organisation. Any team needs motivating, and this requires the qualities of leadership. This sounds, and is, nebulous, but leadership involves embodying the common aim of the practice through a constant striving for its agreed objectives. It can, of course, be expressed by many team members, not least in clinical issues by the doctors and nurses. For the practice manager leadership must involve all the practice members in working to perfect the organisation which provides the essential support to a successful consultation.

Good leaders are not authoritarian, nor are they shrinking violets. They believe in forging consensus and then helping everybody to share in the implementation. They delegate, with support, and with reasonable expectations of an individual's capabilities. They value people for what they can do and help them to recognise and tackle those areas they find difficult.

The practice manager should be tactful and must have a sense of humour. This is just as essential when dealing with difficult patients who want to see "whoever is in charge" as when dealing with rota clashes between receptionists who all want the same holiday weeks. Many patients are not yet familiar with the role and responsibilities of a practice manager, and some 